REVISTA ANDALUZA DE ANTROPOLOGÍA.

NÚMERO 4: ENCRUCIJADAS PARA LAS SOCIEDADES PESQUERAS DEL SUR EN EL MARCO DE LA GLOBALIZACIÓN. MARZO DE 2013

ISSN 2174-6796

[pp. 173-179]

http://dx.doi.org/10.12795/RAA.2013.i04.10

\title{
JIMÉNEZ DE MADARIAGA, CELESTE Y HURTADO SÁNCHEZ, JOSÉ (2012). Andalucía. Identidades culturales y dinámicas sociales. Sevilla: Aconcagua Libros, 340 pp.
}

\section{Victoria Quintero Morón \\ Universidad Pablo de Olavide}

El libro que presentamos empieza y concluye con un análisis situado en torno a la percepción de lo andaluz y de la identidad andaluza: Gabriel Cano nos ubica en un territorio que ha sido percibido como diferenciado y singular desde muy atrás y Fernando Ruiz culmina reflexionando sobre los procesos artísticos contemporáneos como símbolos o definiciones de lo andaluz. Con esta urdimbre que va tramando todo el texto, la compilación de Celeste Jiménez y José Hurtado supone una mirada actualizada a la realidad andaluza y a los modos de analizar Andalucía. La obra tiene una clara vocación de reflexionar sobre la Andalucía del presente y las transformaciones e innovaciones de las cuatro últimas décadas, sin por ello dejar de entender el pasado y los procesos de calado histórico que nos hacen comprender el hoy. Una reflexión, desde el análisis científico y desde la crítica, que se hace cada vez más urgente para estimular el debate social e ir cimentando bases sólidas para propuestas alternativas de futuro.

La secuencia en que se ordena el texto sigue los cánones al uso y va desde ámbitos más generales como el territorio y las dinámicas poblacionales (Gabriel Cano y Jesús Ventura), la conformación histórica de la identidad (Isidoro Moreno) o la economía andaluza (Manuel Delgado) a temáticas más específicas como el turismo (Javier Hernández), la diversidad cultural (Francisco Checa), los movimientos sociales (Talego, Del Río, Coca), el pluralismo religioso (Sol Tarres y Jiménez) y la creación artística (Fernando Ruiz). A 
excepción hecha de Cano y Ventura (geógrafos) y Delgado (economista), los firmantes son mayoritariamente antropólogos, todos ellos profesores en distintas universidades andaluzas y especialistas en los temas que se abordan.

Con el título "Procesos territoriales y dinámicas poblacionales en Andalucía", Gabriel Cano y Jesús Ventura inician el recorrido por la realidad andaluza en una compleja síntesis desde la perspectiva del análisis geográfico regional. Fiel a sus tesis, Gabriel Cano introduce la temática a partir de la continuidad histórica en la delimitación y percepción de Andalucía. A partir de ahí se van describiendo diferentes aspectos físicos y ambientales como la conformación del relieve, las características de la climatología, la vegetación y la situación actual de los recursos hídricos, con especial incidencia en la problemática de la gestión de la Cuenca Hidrográfica del Guadalquivir y las limitaciones competenciales recientemente falladas por el Tribunal Constitucional. Por su parte, Jesús Ventura se centra en los procesos demográficos y el sistema urbano y de ordenación del territorio. Ventura apunta a las altas tasas de analfabetismo funcional o el exponencial incremento de población inmigrante en los últimos 20 años, poco más se indica como nuevo en el poblamiento andaluz, excepción hecha del continuo retroceso de los dispersos y la consolidación de las áreas metropolitanas y litorales. Preocupa al autor el modelo reiteradamente fallido de ordenación del territorio a través de entidades comarcales, que a pesar de estar presente con distintas denominaciones en unos instrumentos u otros, acaban por diluirse en el sistema provincial y se da preeminencia a la gestión frente a potenciales modelos político-identitarios que podrían suponer las agrupaciones de municipios.

Isidoro Moreno escribe el segundo texto: "La identidad histórica de Andalucía". El autor nos recuerda que la construcción de la historia, las narrativas sobre cómo fue el pasado y qué hitos, hechos o acontecimientos se consideran determinantes, son un instrumento fundamental en la definición de las sociedades en el presente y especialmente en la construcción de sus identidades. Desde esta premisa, y en coherencia con sus posicionamientos ideológicos y científicos, Moreno Navarro hace un recorrido por las bases históricas de lo andaluz. En contra de los posicionamientos de otros académicos, el autor incide en cómo precisamente la superposición de temporalidades y la continuidad en la percepción diferenciada del territorio, se configuran como núcleos fundamentales de comprensión y análisis de la identidad andaluza. A través de distintas "etapas en la identidad histórica de Andalucía" el autor defiende la tesis de cambios, de modificaciones políticas y expresivas importantes, pero también de un componente de continuidad, de síntesis. En un recorrido histórico muy rápido se señala el sustrato de continuidad entre los nuevos valores y modos de vida llegados y las fórmulas civilizatorias de Tartessos, la Bética, Al-Andalus y la conquista castellana... Se detiene Moreno en las diferencias en la conquista cristiana de la Andalucía Occidental y el Reino de Granada, y también el papel 
de Sevilla como centro económico y de gestión de la conquista trasatlántica; asimetrías que se trasladarán a diferenciación y desvertebración andaluza. Sin embargo, serán los intereses y pactos de la oligarquía agraria andaluza con otras élites del resto del Estado lo que, según Moreno, paralizará la incipiente industrialización andaluza de la primera mitad del XIX y situará a Andalucía en el estado de dependencia en el que todavía permanece. En consonancia con las aspiraciones del autor de una Andalucía más justa, la denuncia que hace de estos factores de dependencia es relevante para distanciarse de otras lecturas historiográficas o filosóficas y para entender los silenciamientos y renuncias políticas efectuadas por los gobernantes autonómicos. Llegados aquí, se echa a faltar en el texto un mayor detenimiento en los últimos cuarenta años transcurridos desde la muerte del dictador, una temática ya trabajada en profundidad en otras obras del autor y que hubiera engarzado adecuadamente con el punto de inflexión que supone la Transición y al que recurrirán como eje analítico otros autores en este libro.

Un análisis crítico sobre la situación económica de Andalucía es el que propone Manuel Delgado en el artículo titulado "La economía andaluza durante las tres últimas décadas (1981-2011)”. El autor sitúa su diagnóstico alrededor de las reivindicaciones y propuestas del primer Estatuto de Autonomía de Andalucía de 1981 y su segunda redacción en 2007: el derecho al trabajo, la cuestión agraria, el desarrollo industrial y tecnológico, los desequilibrios territoriales, la situación periférica de Andalucía... Solo para comenzar Delgado nos ubica en uno de los datos más demoledores: el crecimiento continuado del desempleo, que se ha triplicado en estas décadas $(34,2 \%$ de la población activa andaluza en 2012) y que tiene un componente estructural. El autor señala de qué modo hoy día la economía agraria andaluza ha ido transformándose en sistemas de monocultivos dependientes de los intereses económicos y financieros de la economía global. La producción hortofrutícola almeriense se revela como una economía de enclave, donde los costes ecológicos y sociales no son contabilizados como tales y recaen sobre los territorios locales, mientras que el valor añadido se aleja cada vez más de los productores y son las grandes cadenas alimentarias las que obtienen los mayores beneficios. Delgado va recorriendo así las problemáticas de externalización y debilidad del olivar o de la industria agroalimentaria, siempre convergentes en una progresiva dependencia. El desequilibrio interno del territorio andaluz y la posición periférica de Andalucía respecto al resto del Estado también ha ido en dirección contraria de lo legislado. Frente a este modelo productivista, externalizado y dependiente, Delgado se sitúa en las tesis de la economía ecológica y demanda una transformación del modelo que apueste por la calidad de la vida, considere los "costes ocultos" y se encamine hacia nuevos paradigmas de consumo, orientados hacia la soberanía alimentaria, poniendo en valor los recursos naturales y los conocimientos locales.

Uno de los aspectos centrales de la economía andaluza que no se contemplan en el 
análisis de Delgado, el turismo, es la temática del artículo que presenta Javier Hernández Ramírez. La propuesta de Hernández tiene una doble componente que la hace original: por una parte, la caracterización del análisis del turismo desde una perspectiva genérica y posicionadamente crítica y por otra parte, plantear un recorrido por los estudios realizados desde la antropología del turismo en Andalucía. Frente a las tesis oficiales y optimistas sobre el turismo, el autor señala que ni el empleo, ni el número de visitantes ni la aportación al PIB son estables, diagnosticando que el actual modelo adolece de una crisis estructural y que no contempla "los efectos no deseados" o costes ecológicos y sociales. El recorrido por los escenarios del litoral, el ámbito rural y la ciudad, nos deja una panorámica negativa, que pone de relieve las contradicciones e insostenibilidales del modelo (expansión inmobiliaria, homogeneización de la oferta, nostalgias estandarizadas, hiperespecialización de los centros históricos...). Por otra parte, Hernández hace un análisis del desarrollo y crecimiento de los estudios antropológicos del turismo en Andalucía en las últimas décadas. La panorámica que muestran los trabajos de antropología del turismo es aún incipiente y por ello fragmentada, aunque se ofrecen perspectivas y fórmulas analíticas potencialmente muy fecundas e innovadoras para el sector. Queda clara para el autor la necesidad de un desarrollo de la perspectiva antropológica para una mejor comprensión del fenómeno. Desde nuestro punto de vista, sin embargo, en el conjunto del artículo se echan de menos algunas miradas más posibilistas y perspectivas positivas sobre el turismo que permitan dirigir el foco hacia un mejor futuro.

Francisco Checa aborda en su texto el complejo entramado de los modelos de gestión de la diversidad cultural y el ámbito de las migraciones en Andalucía. El autor estructura el texto en tres apartados teóricamente secuenciados: los modelos de gestión multiculturales e interculturales; una caracterización de los extranjeros residentes en Andalucía y el contexto andaluz como "laboratorio" para la convivencia intercultural. Checa defiende el modelo intercultural como el más adecuado para superar las "fragmentaciones del multiculturalismo", aboga por una propuesta de cultura para la paz desde una "ciudadanía universal". Con ello se dibuja un marco de posicionamientos teóricos e ideológicos y una propuesta de desiderátums o guías para una sociedad futura. Resulta muy elocuente el panorama que nos dibuja el autor en el segundo apartado, y que desecha el tópico de que la "actual crisis" expulsa población inmigrante: el número de extranjeros en Andalucía se ha multiplicado en la última década (2001-2011) y en paralelo a ello, se ha producido una expansión por todas las provincias y municipios andaluces (que no un equilibrio en su distribución). En la tercera parte, el autor nos propone un recorrido de distintos ámbitos en los que delinear esas pautas de interculturalidad: la escuela, la familia, los medios de comunicación y la sociedad cívica. Esta parte del texto, desde nuestro punto de vista, se queda corta en cuanto a las referencias a casos concretos o a antecedentes académicos que doten de precisión a las propuestas: se vuelve de nuevo a establecer un 
horizonte de lo que sería deseable de las metas utópicas a alcanzar, pero apenas se tratan los procesos reales en los que los colectivos extranjeros se ven inmersos en sus relaciones multiculturales en el ámbito de la escuela, de la sociabilidad vecinal, de las relaciones laborales, del asociacionismo, etc.

Félix Talego, Ángel del Río y Agustín Coca firman el texto "De la protesta: apuntes sobre los movimientos sociales en Andalucía". Es de agradecer este apretado esfuerzo de síntesis que reflexiona sobre los más importantes movimientos sociales en Andalucía, considerados como un agente político y de cambio fundamental en la sociedad -consigan o no los objetivos que se proponen, pero que actúan en sí mismos como revulsivos sociales-. La propuesta es arriesgada en cuanto a la complejidad de la temática, la inmensa producción bibliográfica y el objetivo propuesto por los autores de abarcar fenómenos muy diversos, con efectos sociales y proyecciones temporales dispares: el movimiento andalucista, el movimiento jornalero, el movimiento feminista y en pro de la diversidad sexual, el movimiento ecopacifista, el movimiento memorialista y los movimientos altermundialistas. El reto de integrar todos estos procesos, actores, dinámicas y simbologías -o acciones simbólicas determinantes para los movimientos- en unas pocas páginas era complejo y se consigue una presentación y caracterización adecuada de todos ellos, aunque nos parece que no es igualmente eficaz el esquema propuesto para abordar fenómenos muy centrados en Andalucía -o con gran autonomía y características propias y singulares- (andalucismo, jornaleros) que quedan bien caracterizados y descritos, frente a otros con diverso grado de influencia y dependencia exterior. Destaca la minuciosidad del análisis del movimiento memorialista. Junto a ello, la propuesta de compresión analítica de varios procesos en un mismo movimiento resulta interesante, pero si bien se consigue argumentar consistentemente en las vinculaciones entre ecologismo-pacifismoantimilitarismo, queda más descabalgada respecto al análisis del movimiento feministaLGHTB. Finalmente, resulta muy sugerente la hipótesis de los autores de considerar los movimientos altermundialistas (o antiglobalización) y los movimientos de indignados (o 15-M) más como "movilizaciones" y en cuanto a sus estructuras y agentes como una continuidad de los movimientos ecopacifistas y feministas.

Del artículo "Pluralismo religioso en Andalucía" son autoras Sol Tarrés Chamorro y Celeste Jiménez de Madariaga, que comienzan por remarcar cómo la secularización va de la mano de la ampliación y variabilidad de la demanda y la oferta religiosa, y en ese sentido, el ámbito andaluz no es diferente a otros. Es poco frecuente y muy revelador el esfuerzo de las autoras por hacer un recorrido histórico sobre la diversidad religiosa en Andalucía, especialmente desde el siglo XIX hasta 1967, para comprender la profundidad temporal de algunas de estas confesiones y para desechar una de las creencias más comúnmente asentadas que une "otra religión" con "extranjero". El panorama que se dibuja a partir de la semblanza de Tarrés y Jiménez es de una gran complejidad y diversidad en cuanto al 
número de confesiones, su penetración en los distintos contextos locales, su distribución territorial, etc. Hacen hincapié las autoras en el gran número de fieles andaluces que practican otras religiones de largo recorrido en nuestro territorio y en la explosión de nuevas confesiones habidas en las últimas décadas, no solo de la mano de los extranjeros, sino también ante las demandas de nuevas formas de espiritualidad. La caracterización social de estas confesiones queda descriptiva y más allá de su estatus formal o informal, se echa en falta cierta tipologización o profundización en algunas de las más relevantes. Finaliza este artículo con un estimulante y sin embargo breve epígrafe sobre la invisibilidad de muchas de estas confesiones y las nuevas estrategias que se están desarrollando para conseguir una mayor presencia en el espacio público: institucionalización, más relaciones inter-vecinales, celebraciones rituales y especialmente la difusión de la "obra social".

Fernando Ruiz firma el último capítulo dedicado a las expresiones artísticas en relación a la identidad andaluza. Esta identidad étnica se caracteriza vinculada a cuatro componentes: "memoria, sentido del territorio, relaciones contrastivas con otros y utilización de marcadores distintivos". Las expresiones artísticas realizadas por andaluces son seleccionadas y analizadas en tanto que elementos marcadores de esa identidad, es decir, de un modo u otro serán elementos que diversos sectores sociales propugnan para la construcción de un nosotros diferenciado. A compás con una definición procesual de las identidades, Fernando Ruiz distingue tres etapas fundamentales en cada una de las expresiones seleccionadas: la transición y sus prolegómenos, la consolidación autonómica y la evolución habida en la última década, del año 2000 en adelante. En este recorrido se desgranan con acierto los recorridos, institucionalización, éxitos y debilidades de las diferentes propuestas artísticas: la pintura como expresión fundamental de las artes plásticas (según el autor), el teatro, el cine, la música, la narrativa... En este muy sintético bosquejo de las artes andaluzas y a tenor de los objetivos marcados en el inicio del texto, se echa de menos cierta reflexión sobre los diferentes públicos y formas de recepción de las distintas artes en Andalucía, un análisis que no es ajeno al autor y que nos hubiera dado contrastes entre obras teatrales o pictóricas reconocidas por una minoría y su potencialidad/dificultades para configurarse como símbolos activadores de lo andaluz, frente a la expansión de otras tradiciones como la música, sobre cuyos públicos sí se reflexiona.

De este modo, el libro nos ofrece una visión general y novedosa de temáticas sociales relevantes en Andalucía y nos permite adentrarnos en problemas y dinámicas complejos de una forma sintética y didáctica. Este mismo ejercicio de síntesis, implica necesaria compresión, brevedad y por ello nos lleva a echar en falta algunas páginas más en cada artículo que nos permitan ahondar en éste o aquel aspecto y también entrar en matices y debates. No obstante, la apuesta de los coordinadores ha sido precisamente esa de mostrarnos una realidad, sea el turismo, la identidad, el territorio, el arte andaluz, la 
interculturalidad o los movimientos sociales y empujarnos a querer saber más a través de las pautas estratégicas de comprensión que nos facilitan los especialistas y de las cuantiosas referencias que los autores nos van desgranando. 